\title{
Solos urbanos formados pelo acúmulo de resíduos em Manaus, Amazonas, Brasil
}

\author{
Keila Cristina Pereira ANICETOํㅜ e Adriana Maria Coimbra HORBE ${ }^{2}$
}

\begin{abstract}
RESUMO
Este estudo apresenta dados sobre a mineralogia e a química de dois solos urbanos em Manaus (Horto Minicipal e Novo Israel) formados a partir da disposição e degradação de resíduo urbano em condiçóes tropicais úmidas. Foi determinada a concentraçáo de $\mathrm{Pb}, \mathrm{Cu}, \mathrm{Ni}, \mathrm{Zn}, \mathrm{Mn}, \mathrm{Fe}, \mathrm{Cd}$ e Cr, investigado o grau de contaminaçáo desses elementos no solo e o potencial deles comprometerem a qualidade da água subterrânea. Foi medido o fracionamento geoquímico por lixiviação sequencial dos elementos, além de determinado o $\mathrm{pH}$, teor de matéria orgânica e caracterizados os grupos funcionais dos ácidos húmicos e fúlvicos. Comparativamente esses solos urbanos refletem a composição mineralógica dos solos naturais da região embora a caulinita tenha menor grau de ordenamento cristalino. Contudo, o pH e o conteúdo de matéria orgânica são bem mais elevados. Em termos absolutos ambos os solos têm aproximadamente a mesma sequência de concentração dos elementos: no Horto Municipal $\mathrm{Fe}>\mathrm{Zn}>\mathrm{Mn}>\mathrm{Cu}>\mathrm{Pb}>\mathrm{Cr}>\mathrm{Ni}>\mathrm{Cd}$ e em Novo Israel $\mathrm{Fe}>\mathrm{Zn}>\mathrm{Cu}>\mathrm{Mn}>\mathrm{Pb}>\mathrm{Cr}>\mathrm{Ni}>\mathrm{Cd}$. As maiores acumulaçóes foram nas fraçóes hidróxido de Fe amorfo e óxi-hidróxidos de Fe seguidas da matéria orgânica. Comparativamente, essas fraçôes tiveram maior enriquecimento no Horto Municipal, provavelmente em consequência dos efeitos de envelhecimento dos resíduos, enquanto as mais biodisponíveis e a residual se acumularam mais em Novo Israel. Esse acúmulo nas fases mais móveis em Novo Israel é a causa da contaminação da água subterrânea e indica que o mesmo deve ocorrer no Horto Municipal.
\end{abstract}

PALAVRAS CHAVE: extração sequencial, matéria orgânica, metais pesados, lixôes.

\section{Urban soils formed by the accumulation of waste in Manaus, Amazonas, Brazil}

\section{ABSTRACT}

This study presents the mineralogy and the chemistry of two urban soils in Manaus (Horto Minicipal and Novo Israel) formed by the accumulation and degradation of waste in tropical humid condition. It was quantified the content of $\mathrm{Pb}, \mathrm{Cu}, \mathrm{Ni}, \mathrm{Zn}$, $\mathrm{Mn}, \mathrm{Fe}, \mathrm{Cd}$ e $\mathrm{Cr}$ and investigated the score of the contamination and the capability of these elements affect groundwater quality. It was quantified the geochemical fraction by sequential leaching, besides $\mathrm{pH}$, organic matter content and the functional groups from the humic and fulvic acids were also determined. The urban soils reflect to a considerable extent the mineralogical composition of the natural soil of the region although the kaolinite has lower dregree of cristaline order. They have higher $\mathrm{pH}$ and organic matter content than the natural soil. Both urban soils have almost the same order of concentration elements: in the Horto Municipal $\mathrm{Fe}>\mathrm{Zn}>\mathrm{Mn}>\mathrm{Cu}>\mathrm{Pb}>\mathrm{Cr}>\mathrm{Ni}>\mathrm{Cd}$ and in Novo Israel $\mathrm{Fe}>\mathrm{Zn}>\mathrm{Cu}>\mathrm{Mn}>\mathrm{Pb}>\mathrm{Cr}>\mathrm{Ni}>\mathrm{Cd}$. The higher concentration occurs in the amorphous Fe hydroxide and Fe oxy-hydroxides followed by the organic matter fraction. These fractions have higher enrichment in the Horto Municipal probable in consequence of the ageing process of the waste, while the most exchangeable and the residual fractions have higher enrichment in the Novo Israel. This higher enrichment in the exchangeable phases is the cause of the groundwater contamination in Novo Israel and indicates a similar consequence in the Horto Municipal area.

KEYWORDS: sequential extraction, organic matter, heavy metals, landfill.

\footnotetext{
1 Programa de Pós-Graduação em Geociências - Departamento de Geociências, Universidade Federal do Amazonas, Av. Gal. Rodrigo 0. J. Ramos 3000, CEP 69077-000, Manaus - AM - Brasil

2 Departamento de Geociências, Universidade Federal do Amazonas, Av. Gal. Rodrigo 0. J. Ramos 3000, CEP 69077-000, Manaus - AM - Brasil. 92-3305-4026, ahorbe@ufam.edu.br
} 


\section{INTRODUÇÃO}

A geração de resíduos sólidos por atividades domésticas, industriais e agrícolas é um dos graves problemas ambientais enfrentados pelos grandes centros urbanos. Esses resíduos são uma mistura complexa de materiais orgânicos e inorgânicos com propriedades físicas e químicas variáveis que se acumulam ao longo de estradas, lixôes ou aterros sanitários e cujas características acompanham as transformaçóes tecnológicas e marcam o estágio de desenvolvimento de uma sociedade (Ensinas 2003). Ao serem depositados e se decomporem são incorporados aos constituintes dos solos naturais passando, assim a serem denominados de solos urbanos (Wilcke et al. 1998; Lu et al. 2003; Banat et al. 2005; Zhang et al. 2009 entre outros). Estão englobados nessa classificação os diretamente derivados da decomposiçáo de lixôes ou aterros sanitários, como os que estáo no seu entorno e aqueles expostos a outras influências antrópicas como poeiras e percolação de águas contaminadas.

Os processos atuantes na degradação de resíduos são complexos, pois envolvem múltiplas reações de complexação, redução, precipitação, dissolução, adsorção, troca iônica, entre outras (Bozkurt et al. 2000; Borges e Gomes 2003), além da própria heterogeneidade natural do material que constitui os resíduos acumulados em lixóes.

Ao longo do tempo os resíduos urbanos passam por três etapas de transformaçôes que demandam pelo menos 100 anos de evolução (Bozkut et al. 2000; Ostman et al. 2006). A fase aeróbica é a mais curta e dura enquanto o oxigênio acumulado nos poros for abundante, é seguida da fase anaeróbia quando o oxigênio foi consumido e o $\mathrm{pH}$ é inicialmente ácido devido a grande quantidade de ácidos orgânicos formados por degradação da matéria orgânica. Esta fase evolui para a geração de metano e $\mathrm{pH}$ mais alcalino quando são formadas moléculas orgânicas menores e $\mathrm{CO}_{2}$. Assim que a matéria orgânica é totalmente degradada, se passa a fase de humidificação que é a mais estável e longa e quando o pH é alcalino. Em condiçôes de saturação em água a matéria orgânica pode se manter estável por mais de 500.000 anos (Bozkut et al.1999). Se o resíduo for revolvido essa sequência de fases pode ser revertida ou as reaçôes podem ser aceleradas. Durante essas etapas apenas $0,01 \%$ dos elementos químicos são lixiviados devido a forte atenuação provocada pelos mecanismos de sorção (Bozkut et al. 2000; Flyhammar et al. 1997). Apesar disso, águas subterrâneas e superficiais próximas a depósitos de lixo são normalmente contaminadas (Sisino e Moreira 1996; AbuRukah e Kofahi 2001).

$\mathrm{O} \mathrm{pH}, \mathrm{o} \mathrm{E}_{\mathrm{H}}$ e a presença de substâncias sortivas controlam a mobilidade dos elementos e reduzem o seu potencial de contaminação (Kabata-Pendias e Pendias 1987; McBride et al. 1997; Barbosa e Otero 1999; Bozkut et al. 2000). As principais substâncias sortivas que constituem barreiras à difusão dos elementos, são as unidades funcionais carboxílicas e fenólicas originadas pela dissociação de grupamentos hidroxila da matéria orgânica, além de óxi-hidróxidos de $\mathrm{Fe}, \mathrm{Mn}$ e $\mathrm{Al}$, carbonatos, sulfetos e cloretos (Bozkut et al. 2000; Ostman et al. 2006). Dentre essas substâncias, a matéria orgânica e os óxi-hidróxidos de $\mathrm{Fe}$, devido a maior proporção e a forte capacidade de sorver elementos são os mais importantes, pois atuam em condiçôes distintas. Enquanto o primeiro favorece o ambiente mais ácido e redutor, o segundo necessita de condições mais alcalinas e oxidantes para se formar (McBride et al. 1997; Bozkurt et al. 2000).

Quando a carga química é excessiva e há saturação da capacidade de sorção, os elementos migram por difusão e se tornam fonte de contaminantes para a vegetaçấo ou a água da chuva, ao se infiltrar, os arrasta e contamina a água subterrânea (Barrow 1989; Barbosa e Otero 1999; Bozkut et al. 2000; Alcântara e Camargo 2001; Fontes et al. 2001; Sodré et al. 2001). Mobilização semelhante pode ocorrer se o resíduo/solo for oxigenado o que promove a maior degradação da matéria orgânica, mas neste caso o ambiente favorece a formação de amorfos de Fe e Mn que agem como fortes absorvedores de metais (Östman et al. 2006).

Há dificuldade em comparar diferentes solos urbanos, pois nem sempre são analisados os mesmos elementos e pela mesma técnica analítica, além de não necessariamente serem produto da degradação de lixóes e aterros como descrito anteriormente. Além disso, os elementos tóxicos e a intensidade da contaminaçáo provocada pela deposiçáo de resíduo variam em função do tipo e quantidade de material depositado e das características do substrato (Fontes e Gomes 2003; Covelo et al. 2007). Por exemplo, Sisino e Moreira (1996) constataram que $\mathrm{Mn}, \mathrm{Pb}$ e $\mathrm{Zn}$ são os elementos com maior concentração que $\mathrm{Cd}, \mathrm{Cr}$, $\mathrm{Co}$ e $\mathrm{Ni}$, enquanto em Ostman et al. (2006) foram $\mathrm{Zn}$ e $\mathrm{Cu}$ mais elevados que $\mathrm{Pb}, \mathrm{Ni}$ e Cd. Outro fator que deve ser considerado é o clima a que estão submetidos, pois ambientes tropicais chuvosos propiciam a lixiviação mais intensa, mas ao mesmo tempo favorecem a formaçáo de óxi-hidróxidos de Fe e Mn, que ajudam a fixar os elementos.

Para quantificar o potencial de contaminação dos metais e medir seletivamente a sua distribuição nos constituintes de um material sólido, determina-se o seu modo de ocorrência pela técnica de extração seqüencial (Tessier et al. 1979; Miller et al. 1986; Keller et al. 1994). Apesar dessa técnica não ser eficiente em solubilizar os óxidos mais cristalinos, é considerada eficiente na liberação dos elementos adsorvidos aos constituintes do material sólido (Flyhammar 1997; Lá et al. 2003), que quando móveis são os responsáveis pela contaminaçấo. Assim, pode-se identificar e quantificar de modo eficiente os elementos químicos mais biodisponíveis e prever possíveis efeitos tóxicos, além de avaliar o potencial de 
remobilização de metais e caracterizar as formas de associação elemento/constituinte.

Rocha e Horbe (2006) ao analisarem a água de poços de abastecimento do bairro de Novo Israel onde há um antigo lixão, constataram conteúdos acima do permitido pelo CONAMA em $\mathrm{Fe}, \mathrm{Cd}, \mathrm{Pb}$, Mn e Zn e compostos nitrogenados e os atribuíram aos resíduos acumulados nas proximidades. Com o objetivo de determinar: 1) a influência, 2) o grau de contaminação provocado pelo acúmulo de resíduos em Novo Israel e 3) o potencial de comprometer a qualidade da água subterrânea, foram estudadas as características mineralógicas e da matéria orgânica da porção sólida do solo e a biodisponibilidade de Pb, Cu, Ni, Zn, Mn, Fe, Cd e Cr. De modo a complementar o estudo, foi determinada a influência do tempo de degradaçáo do resíduo, para isso foi estudado um outro solo urbano um pouco mais antigo acumulado a algumas quilômetros de distância, no bairro do Aleixo onde hoje se localiza o Horto Municipal de Manaus. Ambos foram comparados a um solo natural típico da região para determinar a taxa de acumulação.

\section{MATERIAIS E MÉTODOS}

Foram selecionados dois solos urbanos gerados pela degradação de material acumulado em antigos lixóes em Manaus localizados nos bairros do Aleixo (zona centro-oeste) e Novo Israel (zona norte) (Figura 1) submetidos as condiçóes tropicais quentes e úmidas da Amazônia. O lixão do Aleixo foi desativado em 1969, enquanto o de Novo Israel em 1986 e, atualmente a área ocupada por eles está densamente habitada. Em parte do lixão do Aleixo foi instalado um Horto Municipal onde foram coletadas as amostras $\left(60^{\circ} 00^{\prime} 11^{\prime \prime} \mathrm{W}\right.$ e $03^{\circ} 06^{\prime} 11^{\prime}$ 'S), enquanto que no do Novo Israel é retirada até hoje terra preta para comercialização. Próximo a esse local foi feita a amostragem $\left(60^{\circ} 00^{\prime} 54^{\prime \prime} \mathrm{W}\right.$ e $\left.03^{\circ} 01^{\prime} 49^{\prime \prime} \mathrm{S}\right)$. Os resíduos foram acumulados sobre solo natural típico da região que é derivado do intemperismo de arenitos e siltitos da Formação Alter do Chão.

No Horto Municipal, localizado no topo de um platô, a amostragem foi efetuada ao longo do perfil do solo utilizandose um trado manual, enquanto que em Novo Israel, devido à grande quantidade de sacos plásticos a amostragem foi feita aproveitando um desnível mais abrupto na encosta da colina que expôs o perfil do solo. Ambas as coletas, realizadas do topo para a base dos perfis, foram efetuadas em 2006. Nos perfis, com espessura de $7 \mathrm{~m}$ no Horto Municipal e $10 \mathrm{~m}$ em Novo Israel, foram coletas amostras a cada $30 \mathrm{~cm}$ de profundidade num total de 18 e 27 amostras, respectivamente. Para obter parâmetros de referência, foi amostrado $1,5 \mathrm{~m}$ do solo natural (5 amostras a cada $30 \mathrm{~cm}$ ) que ocorre nas proximidades do lixão do Novo Israel e que representa o solo da região. Após secas à temperatura ambiente e a retirada de materiais grossos (cacos de vidro e cerâmica, pregos, material plástico e de construção), as amostras foram desagregadas e quarteadas manualmente. Com base na textura, variabilidade de cor e tipo de material encontrado foram selecionadas 24 amostras para as análises químicas e mineralógicas.

As análises mineralógicas foram realizadas no difratômetro da Shimadzu XRD 6000 do Laboratório de Difração de Raios-x da Universidade Federal do Amazonas. As leituras foram feitas com anodo de $\mathrm{Cu}$, com intervalo de leitura entre $3^{\circ}$ a $60^{\circ} 2 \theta$ para as fraçóes total, areia e silte-argila e de 18 a $22 \circ 2 \theta$ para o estudo do ordenamento da caulinita (Hinckley 1963). As fraçóes areia e silte-argila foram obtidas por separação granulométrica a úmido com peneira de $0,062 \mathrm{~mm}$.

O material desagregado passado em peneira de $2 \mathrm{~mm}$ foi imerso em suspensão solo:água na proporção 1:2,5 e em

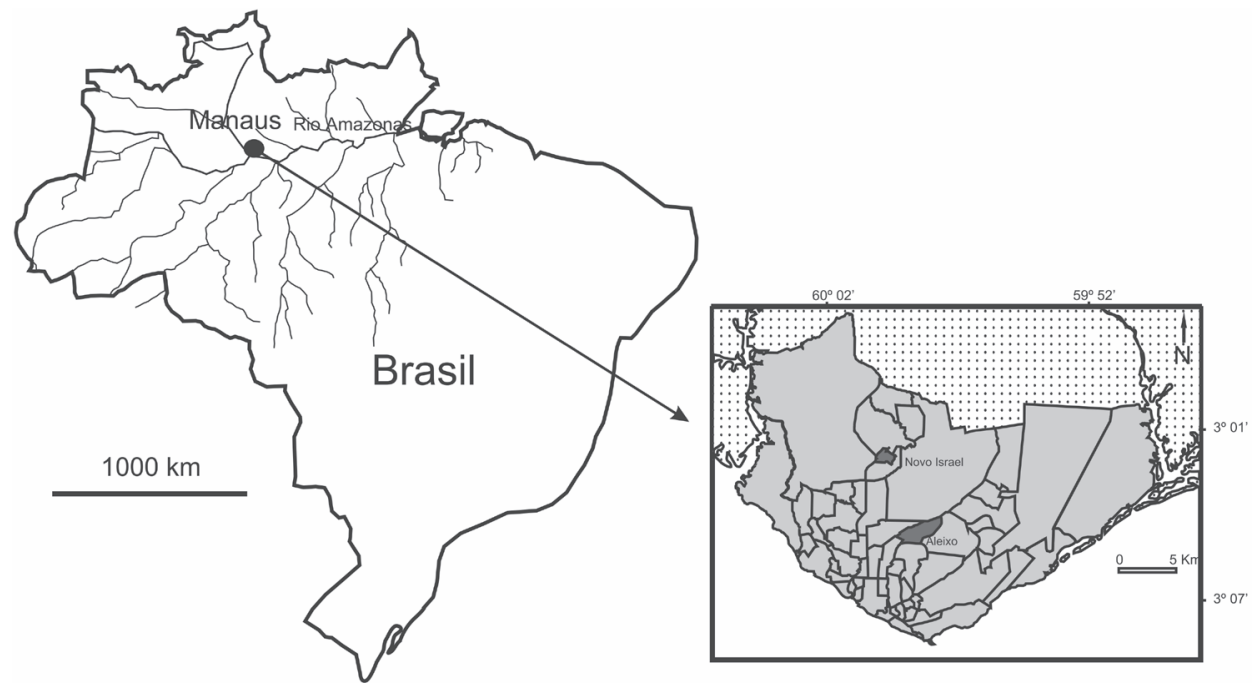

Figura 1 - Mapa de localização dos lixões de Novo Israel e Horto Municipal. 
soluçáo de $\mathrm{KCl} 1 \mathrm{~mol} \mathrm{~L}^{-1}$, mantendo-se a mesma proporção solo:solução. $\mathrm{Na}$ solução foi medido o $\mathrm{pH}$ com eletrodo específico.

$\mathrm{Na}$ determinação da matéria orgânica foi utilizado o método volumétrico pela titulaçấo do excesso de dicromato de potássio com sulfato ferroso amoniacal (EMBRAPA 1997). Para a obtenção dos ácidos húmicos e fúlvicos tomou-se $5 \mathrm{~g}$ do material desagregado, adicionou-se $50 \mathrm{~mL}$ de $\mathrm{HCl} 0,1$ mol.L $\mathrm{L}^{-1}$ e ajustou-se o $\mathrm{pH}$ para $1,5 \mathrm{com} \mathrm{HCl} 1 \mathrm{~mol} \cdot \mathrm{L}^{-1}$. A mistura foi agitada por $1 \mathrm{~h}$, centrifugada por 10 minutos. A seguir ajustou-se o $\mathrm{pH}$ do resíduo para $7 \mathrm{com} \mathrm{NaOH} 1$ mol.L-1 e adicionou-se $50 \mathrm{~mL}$ de $\mathrm{NaOH}$ 0, 1 mol.L-1 ${ }^{-1}$. O sobrenadante foi desprezado. A mistura foi agitada por 4 horas, centrifugada por 10 minutos e o resíduo desprezado (humina). O sobrenadante foi acidificado para $\mathrm{pH}$ 1,5 com HCl 6 mol. $\mathrm{L}^{-1}$ e reservado por uma noite para posterior centrifugação. $\mathrm{O}$ resíduo corresponde ao ácido húmico e a solução ao ácido fúlvico. Ambos foram liofilizados e analisados por espectroscopia de absorção no infravermelho por transformada de Fourier (FT-IR) num Perkin Elmer, Modelo Spectrum 2000 na Central Analítica da Universidade Federal do Amazonas.

Para o procedimento de extraçáo sequencial o material desagregado foi passado em peneira de $0,177 \mathrm{~mm}$. Foram selecionadas seis fraçôes em duplicata para extração em função das características geoquímicas: solúvel em água, trocável e adsorvida, hidróxidos de Fe amorfos, matéria orgânica, óxihidróxidos de Fe e residual a partir da adaptaçáo do método de Tessier (Tessier et al. 1979). Foram utilizados, respectivamente os seguintes extratores sob agitação: 1) água pura por 2 horas, 2) ácido acético $1 \mathrm{~mol} \mathrm{~L}^{-1}$ +acetado de sódio $1 \mathrm{~mol} \mathrm{~L}^{-1}$ por 5 horas, 3) oxalato de amônio $0,175 \mathrm{~mol} \mathrm{~L}^{-1}+$ ácido oxálico 0,1 mol L ${ }^{-1}$ por 4 horas, 4) peróxido de hidrogênio $30 \%(\mathrm{~m} / \mathrm{v})$ e ácido nítrico $0,02 \mathrm{~mol} \mathrm{~L}^{-1}$ a $85^{\circ} \mathrm{C}$ por 1 horas e 5) cloridrato de hidroxilamina $1 \mathrm{~mol} \mathrm{~L}^{-1}$ e ácido acético $25 \%(\mathrm{v} / \mathrm{v})$ por 5 horas. A fração residual (6) foi digerida com ácido fluorídrico e perclórico puros a quente até a total dissolução do material.

Após cada extraçáo o sobrenadante, contendo o material dissolvido, foi separado do resíduo por centrifugação durante 10 minutos. O resíduo foi lavado com água deionizada e depois centrifugado. A água de lavagem foi descartada e o resíduo submetido à extração seguinte. Depois de filtrado e acidificado com $\mathrm{HNO}_{3}$, o sobrenadante foi analisado para $\mathrm{Pb}, \mathrm{Cu}, \mathrm{Ni}, \mathrm{Zn}, \mathrm{Mn}, \mathrm{Fe}, \mathrm{Cd}$, e Cr no espectrofotômetro de absorção atômica com chama Perkin Elmer 3300 da Central Analítica da Universidade Federal do Amazonas. Para efeito de quantificação foram preparados padróes a partir de soluçôes certificadas de $1000 \mathrm{ppm}$ para cada elemento.

Os valores de acumulaçáo foram calculados usando a fórmula: $F A=A_{R} / A_{N}$, onde $A_{R}$ é a média do elemento na amostra do resíduo e $\mathrm{A}_{\mathrm{N}}$ da amostra do material natural.

\section{RESULTADOS}

\section{Características físicas}

O solo urbano resultante da degradação do resíduo acumulado no Horto Municipal tem aproximadamente $7 \mathrm{~m}$ de espessura, apresenta estrutura friável, textura argilo-arenosa e cor amarelada na base, enquanto é areno-argiloso, marrom a preto da porção intermediária até o topo. Uma variedade de resíduos encontra-se misturada ao material fino do solo, principalmente restos metálicos e cacos de porcelana e vidro. Não há informação sobre a origem e tipo dos resíduos, mas considerando que foi desativado em 1969 e anterior ao início do Distrito Industrial de Manaus, a maior parte dele deve ser de origem doméstica, portanto com predomínio de material orgânico.

O solo resultante da degradação dos resíduos acumulados em Novo Israel tem aproximadamente $10 \mathrm{~m}$ de espessura, é friável, constituído por três zonas acinzentadas argilo-arenosas de aproximadamente $1 \mathrm{~m}$ de espessura cada uma, alternadas por porçôes areno-argilosas de até $2 \mathrm{~m}$ avermelhadas e marrons. Foi encontrada grande quantidade de sacos plásticos, restos metálicos e cacos de vidro e de material de construçáo. Levantamento realizado por Lima (1991) sobre o tipo de material recolhido em Manaus, apesar de ser posterior a desativação do lixão de Novo Israel em 1986, sugere que a maior parte do material acumulado é constituído de matéria orgânica, papel e papelăo (80\%).

O solo natural tem $1,5 \mathrm{~m}$ de espessura, é argilo-arenoso, friável, constituído de areia fina a média, tem coloração vermelha a amarelo-rosada na base e amarelo a cinza em direção ao topo.

\section{Composição mineralógica}

Os solos são compostos majoritariamente por caulinita e quartzo, enquanto na fração silte, além desses minerais, ocorre anatásio, goethita, hematita, illita/muscovita e outros não identificados (Figura 2). Desses a calcita ocorre exclusivamente no resíduo do Novo Israel e provavelmente está associada a restos de material de construção. $\mathrm{Na}$ fração argila os difratogramas de raios-x apresentaram background mais elevado entre $20^{\circ}$ e $30^{\circ} 2 \theta$, exceto no material natural, o que indica a presença de material amorfo.

$\mathrm{O}$ estudo de detalhe entre $18^{\circ}$ e $22^{\circ} 2 \theta$ mostra que a caulinita presente nos três locais estudados apresenta suas três reflexões típicas em 020, 110 e 111, contudo próximo a superfície elas se deterioram e desaparecem totalmente, especialmente no Horto Municipal e em Novo Israel (Figura 2). Isso mostra desordenamento crescente da sua estrutura e se reflete no tamanho minúsculo dos cristalitos $<1 \mu \mathrm{m}$ de diâmetro. 


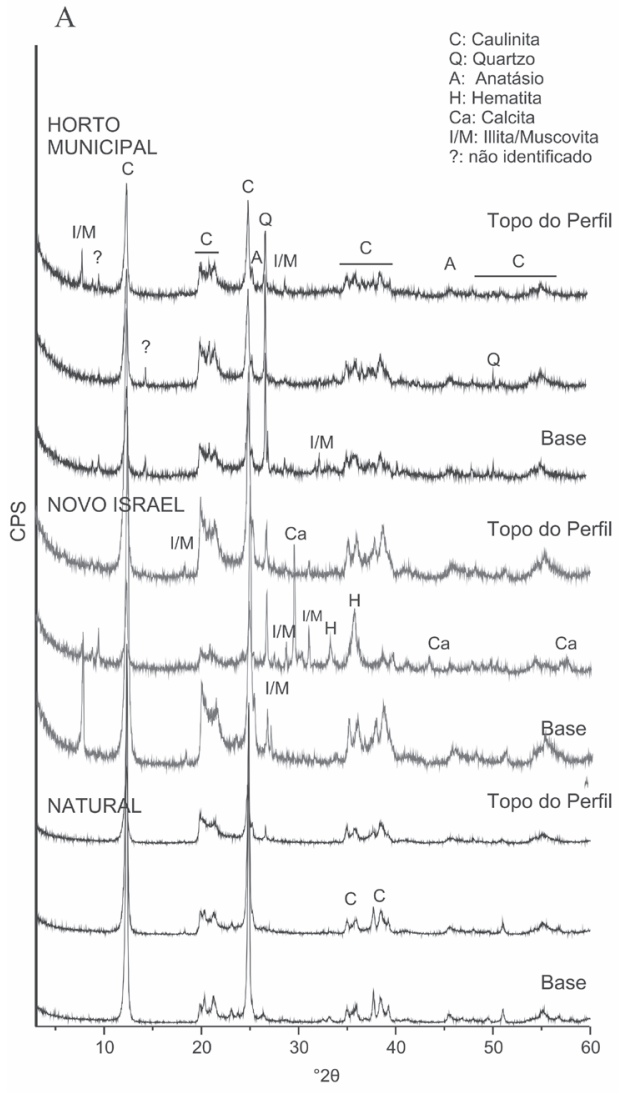

B

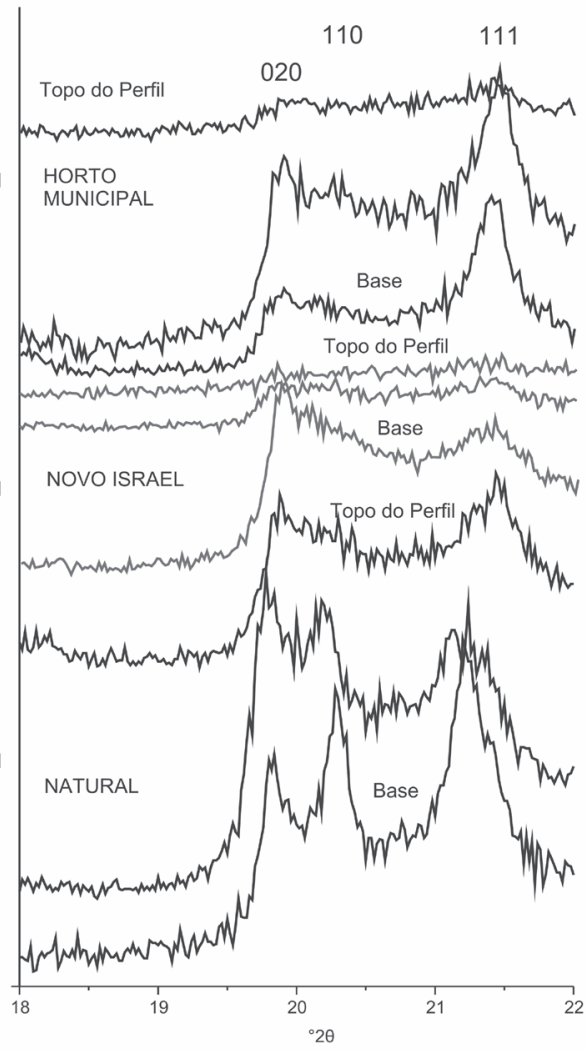

Figura 2 - A- Difratogramas da fração total com identificação das reflexões dos minerais presentes; B- Difratogramas da fração silte-argila que mostra a diminuição da intensidade das reflexões da caulinita em direção ao topo dos solos em consequência do seu desordenamento crescente.

\section{Análises físico-químicas}

$\mathrm{Na}$ tabela 1 estáo apresentados os resultados de $\mathrm{pH}$ em água e $\mathrm{KCl}$ e o conteúdo de matéria orgânica. $\mathrm{O} \mathrm{pH}$, além de medir a acidez, determina a carga líquida que predomina no material e a mudança em seu caráter eletroquímico. Uma característica marcante do solo urbano é o $\mathrm{pH}$ próximo da neutralidade em relaçáo a maior acidez no material natural (Tabela 1). Outro fato importante é a carga superficial, essencialmente negativa ( $\Delta \mathrm{pH}$ negativos) no material natural, enquanto no Horto Municipal é tanto negativa como positiva e em Novo Israel predominantemente positiva (Tabela 1).

O conteúdo de matéria orgânica varia ao longo dos solos, é menor e crescente em direçáo ao topo no solo natural (1,3 a 6,9\%), enquanto no Horto Municipal alcança seu maior valor entre 30 e $60 \mathrm{~cm}$ de profundidade (de 0,6 a 12,97\%) e em Novo Israel com maior conteúdo entre 60 e $90 \mathrm{~cm}$ (de 2,3 a 15,8\%) (Tabela 1).

No espectro de infravermelho as bandas de absorçóes dos ácidos húmicos e fúlvicos mostram a presença de alcoóis, fenóis ou ácidos carboxílicos e estiramento N-H (3464-2900 $\left.\mathrm{cm}^{-1}\right)$, estiramentos $\mathrm{C}=\mathrm{O}$ de cetonas $\left(1717 \mathrm{~cm}^{-1}\right)$ e aminas $\left(1653 \mathrm{~cm}^{-1}\right)$, vibraçóes de estiramento $\mathrm{C}=\mathrm{C}$ de alcenos, $\mathrm{C}=\mathrm{O}$ de quinonas, amidas e grupos carboxílicos e íon $\mathrm{COO}^{-}(1630-$ $1620 \mathrm{~cm}^{-1}$ ) em ambos os solos (Figura 3). Há indicativo da presença de compostos alifáticos $\left(1456 \mathrm{~cm}^{-1} \mathrm{e} 1384 \mathrm{~cm}^{-1}\right) \mathrm{e}$ grupos carboxílicos complexados com ferro $\left(1398-1261 \mathrm{~cm}^{-1}\right)$. As bandas em 3692 e $3622 \mathrm{~cm}^{-1}$, bem como entre 1100 e 1000 $\mathrm{cm}^{-1}$ e em $914 \mathrm{~cm}^{-1}$ podem ser atribuídas a ligaçóes $\mathrm{Si}-\mathrm{OH}$ resultantes de impurezas (caulinita) no processo de purificação.

De forma geral, os espectros de infravermelho do Horto Municipal e Novo Israel são similares entre si e com a matéria orgânica de solos naturais da região (Horbe et al. 2004), apenas a amostra da base do perfil do Horto Municipal apresentou ausência das bandas características de cetonas e ácidos carboxílicos e dos compostos alifáticos o que indica menor influência dos resíduos.

\section{As frações geoquímicas}

$\mathrm{Na}$ fração solúvel em água o $\mathrm{Zn}$ foi o elemento com maior contribuição na composição química (Figura 4). O Horto Municipal apresenta concentrações significativas apenas para $\mathrm{Zn}$ (até $904 \mu \mathrm{g} \cdot \mathrm{kg}^{-1}$ ), encontrado em todo o solo e, contribuição bem menor de $\mathrm{Cu}$ na porção intermediária 
Tabela 1 - Valores de $\mathrm{pH}$ em $\mathrm{KCl}$ e $\mathrm{H}_{2} \mathrm{O}$ e conteúdo de matéria orgânica (\% em peso) nos solos urbanos do Horto Municipal (Aleixo) e Novo Israel e no solo natural.

\begin{tabular}{|c|c|c|c|c|c|}
\hline Local & $\begin{array}{l}\text { Profundidade } \\
(\mathrm{m})\end{array}$ & $\mathrm{KCl}$ & $\mathrm{H}_{2} \mathrm{O}$ & $\begin{array}{c}\Delta \mathrm{pH}=\mathrm{pH}_{\mathrm{KCl}} \\
-\mathrm{pH}_{\mathrm{H} 2 \mathrm{O}}\end{array}$ & $\begin{array}{c}\text { Matéria } \\
\text { Orgânica }\end{array}$ \\
\hline \multirow{8}{*}{$\begin{array}{l}\text { Horto } \\
\text { Municipal }\end{array}$} & 0,3 & 6,46 & 6,50 & $-0,04$ & 8,4 \\
\hline & 1,5 & 7,26 & 7,13 & 0,13 & 12,9 \\
\hline & 2,1 & 7,26 & 7,03 & 0,23 & 9,3 \\
\hline & 3,0 & 7,11 & 6,90 & 0,21 & 10,1 \\
\hline & 3,6 & 7,14 & 7,23 & $-0,09$ & 9,4 \\
\hline & 4,8 & 7,75 & 7,33 & 0,42 & 6,5 \\
\hline & 5,7 & 7,11 & 6,95 & $-0,16$ & 6,0 \\
\hline & 6,9 & 5,84 & 6,69 & $-0,85$ & 0,6 \\
\hline & & & & Média & 7,9 \\
\hline \multirow{12}{*}{ Novo Israel } & 0,3 & 6,50 & 6,26 & 0,24 & 5,3 \\
\hline & 0,9 & 7,16 & 6,95 & 0,21 & 12,0 \\
\hline & 1,5 & 7,23 & 7,00 & 0,23 & 15,8 \\
\hline & 2,4 & 7,57 & 7,46 & 0,11 & 2,3 \\
\hline & 3,0 & 7,60 & 7,37 & 0,23 & 4,7 \\
\hline & 3,9 & 7,50 & 7,48 & 0,02 & 7,9 \\
\hline & 4,8 & 7,39 & 7,38 & 0,01 & 9,3 \\
\hline & 6,3 & 7,18 & 6,75 & 0,43 & 8,6 \\
\hline & 8,1 & 7,36 & 7,35 & 0,01 & 7,2 \\
\hline & 9,0 & 7,69 & 7,63 & 0,06 & 5,2 \\
\hline & 9,7 & 7,07 & 7,26 & $-0,19$ & 10,9 \\
\hline & & & & Média & 8,1 \\
\hline \multirow{6}{*}{ Natural } & 0,3 & 4,61 & 4,69 & $-0,08$ & 6,9 \\
\hline & 0,6 & 4,21 & 5,33 & $-1,12$ & 0,8 \\
\hline & 0.9 & 4,65 & 5,84 & $-1,10$ & 0,5 \\
\hline & 1,2 & 4,48 & 6,09 & $-1,61$ & 1,0 \\
\hline & 1,5 & 4,72 & 6,33 & $-1,61$ & 1,3 \\
\hline & & & & Média & 2,1 \\
\hline
\end{tabular}

e no topo (até $42 \mu \mathrm{g} \cdot \mathrm{kg}^{-1}$ ) (Tabela 2 e figura 4). Em Novo Israel Zn (valor máximo de $1244 \mu \mathrm{g} . \mathrm{kg}^{-1}$ ) seguido de $\mathrm{Mn}$ e $\mathrm{Cu}$ (até 92 e $60 \mu \mathrm{g} \cdot \mathrm{kg}^{-1}$ respectivamente) são os elementos que apresentam as maiores contribuiçóes (Figura 4), enquanto $\mathrm{Pb}$ e Ni têm menores concentrações e distribuição errática (de < 0,5 a $19 \mu \mathrm{g} \cdot \mathrm{kg}^{-1} \mathrm{e}<0,5$ a $66 \mu \mathrm{g} \cdot \mathrm{kg}^{-1}$ respectivamente) (Tabela 2). Em ambos os solos urbanos Fe e Cr mostram teores abaixo do limite de detecçấo. No solo natural, além do Zn (até 996 $\left.\mu \mathrm{g} \cdot \mathrm{kg}^{-1}\right)$ e $\mathrm{Mn}\left(5\right.$ a $22 \mu \mathrm{g} \cdot \mathrm{kg}^{-1}$ ) ao longo de todo o perfil, foi detectado $\mathrm{Cu}$ e Fe (até 2 e $715 \mu \mathrm{g} \cdot \mathrm{kg}^{-1}$ respectivamente) no topo e $\mathrm{Cd}$ na base (até $8 \mu \mathrm{g} \cdot \mathrm{kg}^{-1}$ ) (Tabela 2).

$\mathrm{Na}$ fração trocável e adsorvida ocorreu maior diversificação na composição química, com $\mathrm{Zn}$ e Mn mais abundantes no Horto Municipal e em Novo Israel enquanto que no solo natural tem maior variabilidade (Figura 4). O Cr está sistematicamente abaixo do limite de detecção nesta fração, $\mathrm{Cd}$ ocorre apenas na base do solo do Horto Municipal $\left(8 \mu \mathrm{g} \cdot \mathrm{kg}^{-1}\right)$ e Fe apenas no topo do Novo Israel $\left(548 \mu \mathrm{g} \cdot \mathrm{kg}^{-1}\right)$ (Tabela 2).
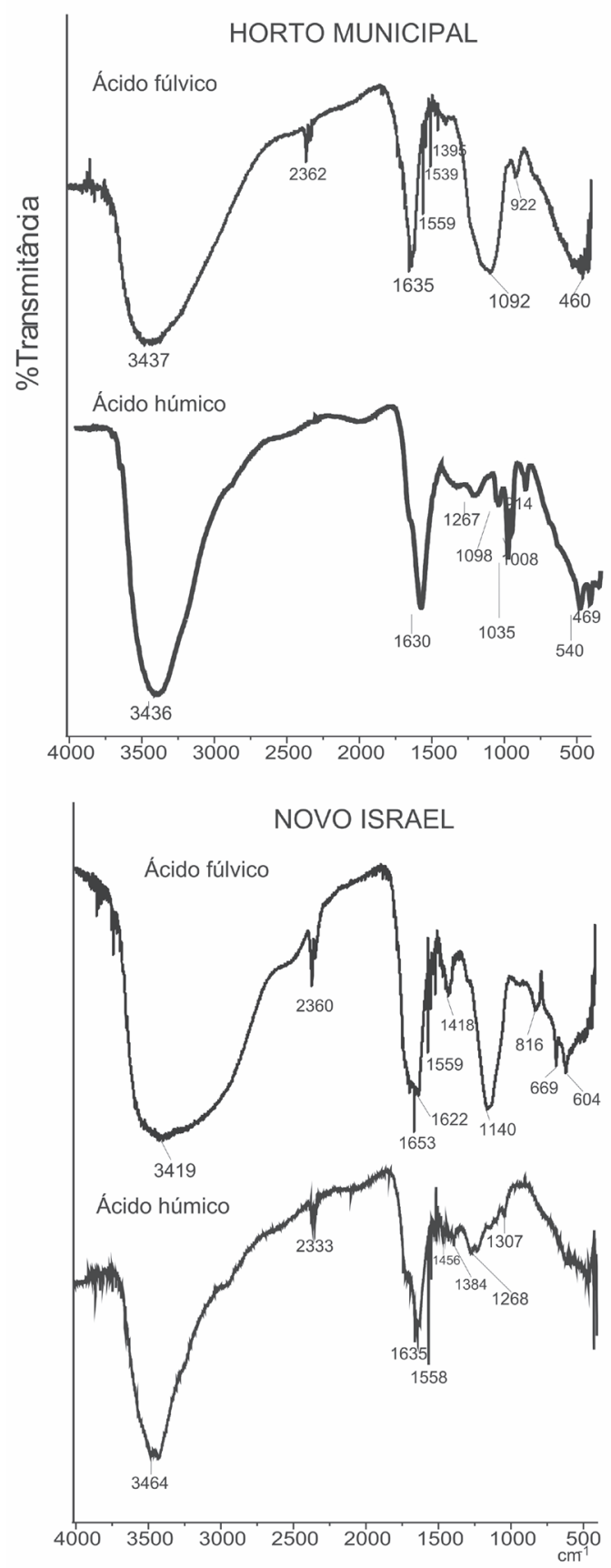

Figura 3 - Espectros de infravermelho dos ácidos fúlvico e húmico obtido pela separação da matéria orgânica dos solos urbanos estudados.

Zinco e Mn são os mais abundantes, tanto no Horto Municipal (até $10869 \mu \mathrm{g} \cdot \mathrm{kg}^{-1}$ e $5237 \mu \mathrm{g} \cdot \mathrm{kg}^{-1}$, respectivamente) como no Novo Israel (até $5400 \mu \mathrm{g} \cdot \mathrm{kg}^{-1} \mathrm{e} 3948 \mu \mathrm{g} \cdot \mathrm{kg}^{-1}$, respectivamente). A diferença entre os solos está que, enquanto $\mathrm{Zn}$ e Mn são mais elevados no Horto Municipal, $\mathrm{Cu}, \mathrm{Pb}$ e $\mathrm{Ni}$ são mais persistentes e elevados em Novo Israel (até 2122, 1063 e 179 $\left.\mu \mathrm{g} \cdot \mathrm{kg}^{-1}\right)$. No solo natural somente Ni está acima do limite de 


\section{ACTA AMAZONICA}

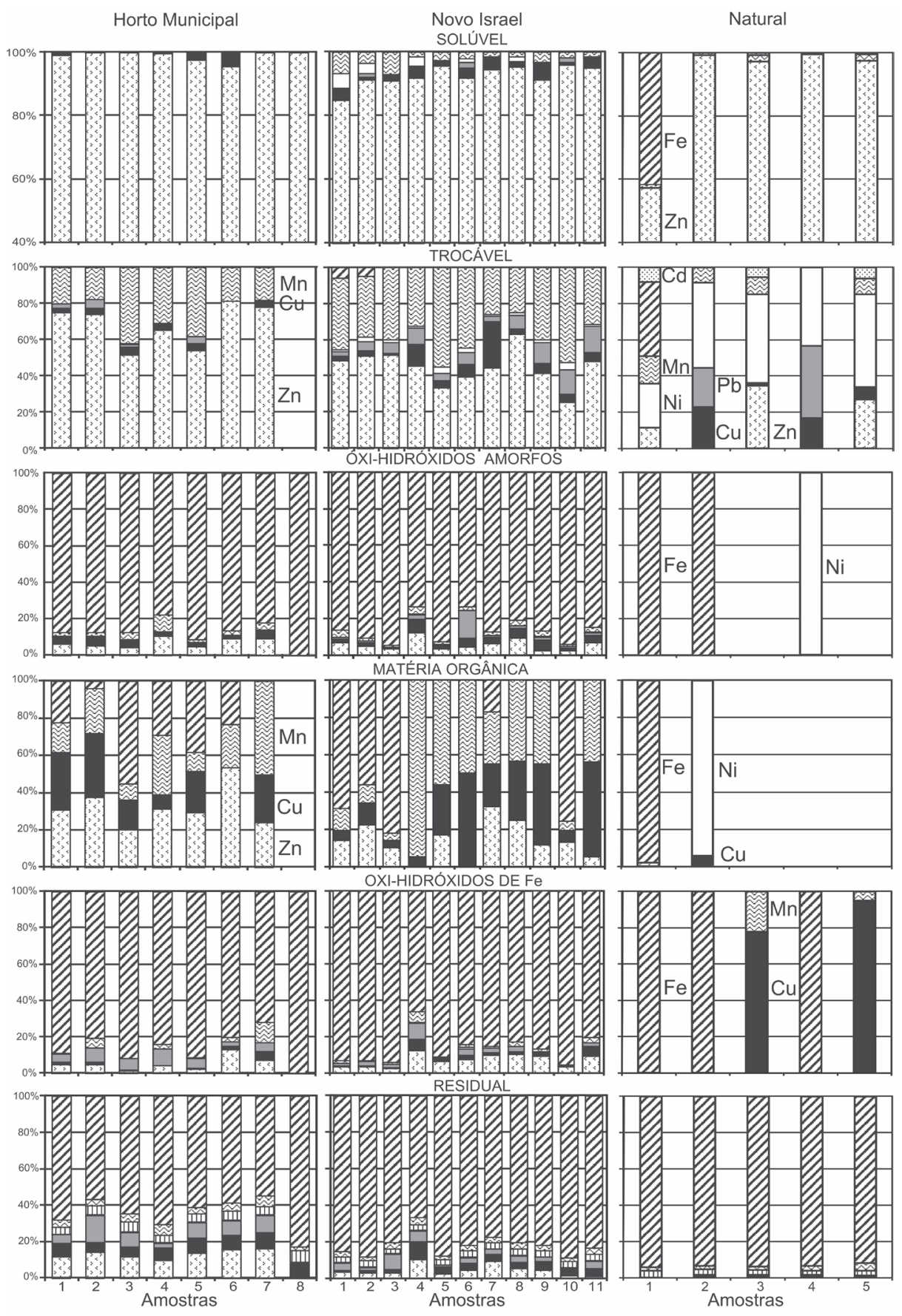

Figura 4 - Proporção dos elementos nas amostras dos solos urbanos do Horto Municipal e Novo Israel e no solo natural (amostra $1=$ topo).

detecção em todo o pacote (entre 46 a $89 \mu \mathrm{g} \cdot \mathrm{kg}^{-1}$ ), os demais são erráticos e com conteúdo baixo $\left(<150 \mu \mathrm{g} \cdot \mathrm{kg}^{-1}\right)$.

$\mathrm{Na}$ fração hidróxidos de ferro amorfos, o conteúdo dos elementos analisados é maior que nas fraçóes anteriores. A principal diferença entre os dois solos está no $\mathrm{Ni}$ abaixo do limite de detecçáo e no baixo conteúdo de $\mathrm{Pb}$ no Horto Municipal. Cromo e Cd estão abaixo do limite de detecção tanto nos solos urbanos quanto no solo natural. O Fe é o elemento mais abundante por constituir os minerais dissolvidos nesta extraçáo (até $183040 \mu \mathrm{g} \cdot \mathrm{kg}^{-1}$ no Horto Municipal e $182160 \mu \mathrm{g} . \mathrm{kg}^{-1}$ no Novo Israel) e é seguido de $\mathrm{Zn}$ (até $22288 \mu \mathrm{g} \cdot \mathrm{kg}^{-1}$ no Horto Municipal e $17192 \mu \mathrm{g} \cdot \mathrm{kg}^{-1}$ no Novo Israel) e Cu (até $9352 \mu \mathrm{g} . \mathrm{kg}^{-1}$ no Horto Municipal e $10648 \mu \mathrm{g} \cdot \mathrm{kg}^{-1}$ no Novo Israel) (Tabela 2, Figura 5). No solo 
Tabela 2 - Teores dos elementos nas frações dos solos urbanos do Horto Municipal (HM) e de Novo Israel (NI) e no solo natural (N). Quando ausente o mínimo corresponde a $<0,5 \mu \mathrm{g} \cdot \mathrm{kg}^{-1}$.

\begin{tabular}{|c|c|c|c|c|c|c|c|c|c|c|}
\hline & & $\mathrm{ppb}$ & $\mathrm{Zn}$ & $\mathrm{Cu}$ & $\mathrm{Pb}$ & $\mathrm{Ni}$ & $\mathrm{Cr}$ & $\mathrm{Mn}$ & $\mathrm{Fe}$ & $\mathrm{Cd}$ \\
\hline \multirow{8}{*}{ 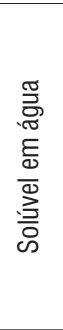 } & \multirow{2}{*}{$\mathrm{HM}$} & Média & 870 & 10 & $<0,5$ & $<0,5$ & $<0,5$ & $<0,5$ & $<0,5$ & $<0,5$ \\
\hline & & Máximo & 904 & 42 & $<0,5$ & $<0,5$ & $<0,5$ & $<0,5$ & $<0,5$ & $<0,5$ \\
\hline & \multirow{3}{*}{$\mathrm{NI}$} & Média & 1059 & 32 & 5 & 16 & $<0,5$ & 36 & $<0,5$ & $<0,5$ \\
\hline & & Máximo & 1244 & 60 & 19 & 66 & $<0,5$ & 92 & $<0,5$ & $<0,5$ \\
\hline & & Mínimo & 918 & 8 & $<0,5$ & $<0,5$ & $<0,5$ & 16 & $<0,5$ & $<0,5$ \\
\hline & \multirow{3}{*}{$N$} & Média & 983 & $<0,5$ & $<0,5$ & $<0,5$ & $<0,5$ & 15 & 144 & 3 \\
\hline & & Máximo & 996 & 2 & $<0,5$ & $<0,5$ & $<0,5$ & 22 & 715 & 8 \\
\hline & & Mínimo & 972 & $<0,5$ & $<0,5$ & $<0,5$ & $<0,5$ & 5 & $<0,5$ & $<0,5$ \\
\hline \multirow{8}{*}{ 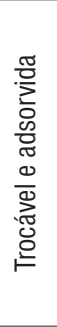 } & \multirow{2}{*}{$\mathrm{HM}$} & Média & 4400 & 219 & 128 & 4 & $<0,5$ & 1964 & $<0,5$ & 2 \\
\hline & & Máximo & 10869 & 518 & 368 & 13 & $<0,5$ & 5237 & $<0,5$ & 9 \\
\hline & \multirow{3}{*}{$\mathrm{NI}$} & Média & 3227 & 506 & 470 & 114 & $<0,5$ & 2497 & 86 & $<0,5$ \\
\hline & & Máximo & 5400 & 2122 & 1063 & 179 & $<0,5$ & 3948 & 548 & $<0,5$ \\
\hline & & Mínimo & 587 & 109 & 113 & 42 & $<0,5$ & 1237 & 1 & $<0,5$ \\
\hline & \multirow{3}{*}{$\mathrm{N}$} & Média & 28 & 12 & 16 & 70 & $<0,5$ & 18 & 31 & 10 \\
\hline & & Máximo & 55 & 24 & 58 & 89 & $<0,5$ & 55 & 150 & 29 \\
\hline & & Mínimo & $<0,5$ & $<0,5$ & $<0,5$ & 46 & $<0,5$ & $<0,5$ & $<0,5$ & $<0,5$ \\
\hline \multirow{8}{*}{ 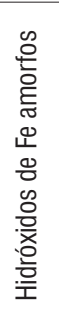 } & \multirow{3}{*}{$\mathrm{HM}$} & Média & 10828 & 5603 & 73 & $<0,5$ & $<0,5$ & 5838 & 132589 & $<0,5$ \\
\hline & & Máximo & 22288 & 9352 & 578 & $<0,5$ & $<0,5$ & 19760 & 183040 & $<0,5$ \\
\hline & & Mínimo & $<0,5$ & $<0,5$ & $<0,5$ & $<0,5$ & $<0,5$ & $<0,5$ & 6397 & $<0,5$ \\
\hline & \multirow{3}{*}{$\mathrm{NI}$} & Média & 8503 & 5347 & 3420 & 342 & $<0,5$ & 3584 & 132816 & $<0,5$ \\
\hline & & Máximo & 17192 & 10648 & 18888 & 607 & $<0,5$ & 7391 & 182160 & $<0,5$ \\
\hline & & Mínimo & 2378 & 531 & 372 & $<0,5$ & $<0,5$ & 976 & 93920 & $<0,5$ \\
\hline & \multirow{2}{*}{$\mathrm{N}$} & Média & $<0,5$ & $<0,5$ & $<0,5$ & 13 & $<0,5$ & $<0,5$ & 6478 & $<0,5$ \\
\hline & & Máximo & $<0,5$ & $<0,5$ & $<0,5$ & 59 & $<0,5$ & $<0,5$ & 32168 & $<0,5$ \\
\hline \multirow{7}{*}{ 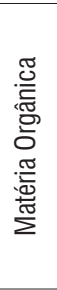 } & \multirow{2}{*}{ HM } & Média & 9319 & 4786 & $<0,5$ & $<0,5$ & $<0,5$ & 7773 & 8507 & $<0,5$ \\
\hline & & Máximo & 32168 & 8936 & $<0,5$ & $<0,5$ & $<0,5$ & 33218 & 30406 & $<0,5$ \\
\hline & \multirow{3}{*}{$\mathrm{NI}$} & Média & 3747 & 2621 & 4 & 2 & $<0,5$ & 3411 & 17226 & $<0,5$ \\
\hline & & Máximo & 13154 & 4986 & 36 & 10 & $<0,5$ & 7029 & 106788 & $<0,5$ \\
\hline & & Mínimo & $<0,5$ & 157 & $<0,5$ & $<0,5$ & $<0,5$ & 821 & $<0,5$ & $<0,5$ \\
\hline & \multirow{2}{*}{$N$} & Média & 116 & 2 & $<0,5$ & 18 & $<0,5$ & 16 & 6172 & $<0,5$ \\
\hline & & Máximo & 574 & 5 & $<0,5$ & 85 & $<0,5$ & 76 & 30855 & $<0,5$ \\
\hline \multirow{8}{*}{ 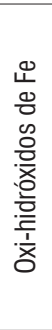 } & \multirow{3}{*}{$\mathrm{HM}$} & Média & 6145 & 1752 & 8936 & $<0,5$ & $<0,5$ & 3980 & 120593 & $<0,5$ \\
\hline & & Máximo & 11351 & 4677 & 19824 & $<0,5$ & $<0,5$ & 12822 & 190840 & $<0,5$ \\
\hline & & Mínimo & $<0,5$ & $<0,5$ & $<0,5$ & $<0,5$ & $<0,5$ & $<0,5$ & 6506 & $<0,5$ \\
\hline & & Média & 8955 & 2735 & 3597 & 236 & $<0,5$ & 2323 & 123875 & $<0,5$ \\
\hline & $\mathrm{NI}$ & Máximo & 17390 & 9508 & 13401 & 1007 & $<0,5$ & 9313 & 203910 & $<0,5$ \\
\hline & & Mínimo & 3278 & 403 & 362 & $<0,5$ & $<0,5$ & 102 & 89310 & $<0,5$ \\
\hline & $N$ & Média & $<0,5$ & 21 & $<0,5$ & $<0,5$ & $<0,5$ & 2 & 4481 & $<0,5$ \\
\hline & IN & Máximo & $<0,5$ & 46 & $<0,5$ & $<0,5$ & $<0,5$ & 6 & 19399 & $<0,5$ \\
\hline & & Média & 12274 & 7193 & 7405 & 403 & 4862 & 4086 & 63921 & 297 \\
\hline & HM & Máximo & 18635 & 10685 & 16942 & 770 & 5740 & 6806 & 64900 & 420 \\
\hline & & Mínimo & 505 & 5235 & 168 & 79 & 3368 & 1816 & 60720 & 115 \\
\hline$\overline{\widetilde{\widetilde{T}}}$ & & Média & 22361 & 18348 & 16419 & 1697 & 15397 & 13434 & 385305 & 856 \\
\hline$\frac{\vec{z}}{w}$ & $\mathrm{NI}$ & Máximo & 59250 & 56650 & 41220 & 2887 & 17925 & 22595 & 398700 & 1122 \\
\hline$\ddot{\simeq}$ & & Mínimo & 5575 & 4935 & 2482 & 1107 & 12725 & 6880 & 366000 & 742 \\
\hline & & Média & 252 & 2973 & $<0,5$ & 1287 & 10423 & 9524 & 353010 & 913 \\
\hline & $\mathrm{N}$ & Máximo & 418 & 4035 & $<0,5$ & 1468 & 11790 & 16525 & 360150 & 1054 \\
\hline & & Mínimo & 91 & $<0,5$ & $<0,5$ & 879 & 9135 & 6640 & 347250 & 690 \\
\hline & HM & Total & 350693 & 156500 & 132345 & 3291 & 38935 & 189131 & 2604890 & 2424 \\
\hline & $\mathrm{NI}$ & Total & 508507 & 325812 & 264838 & 25451 & 170724 & 280688 & 7226809 & 9426 \\
\hline & $\mathrm{N}$ & Total & 6902 & 15051 & 107 & 6948 & 52140 & 47880 & 1851576 & 4642 \\
\hline
\end{tabular}




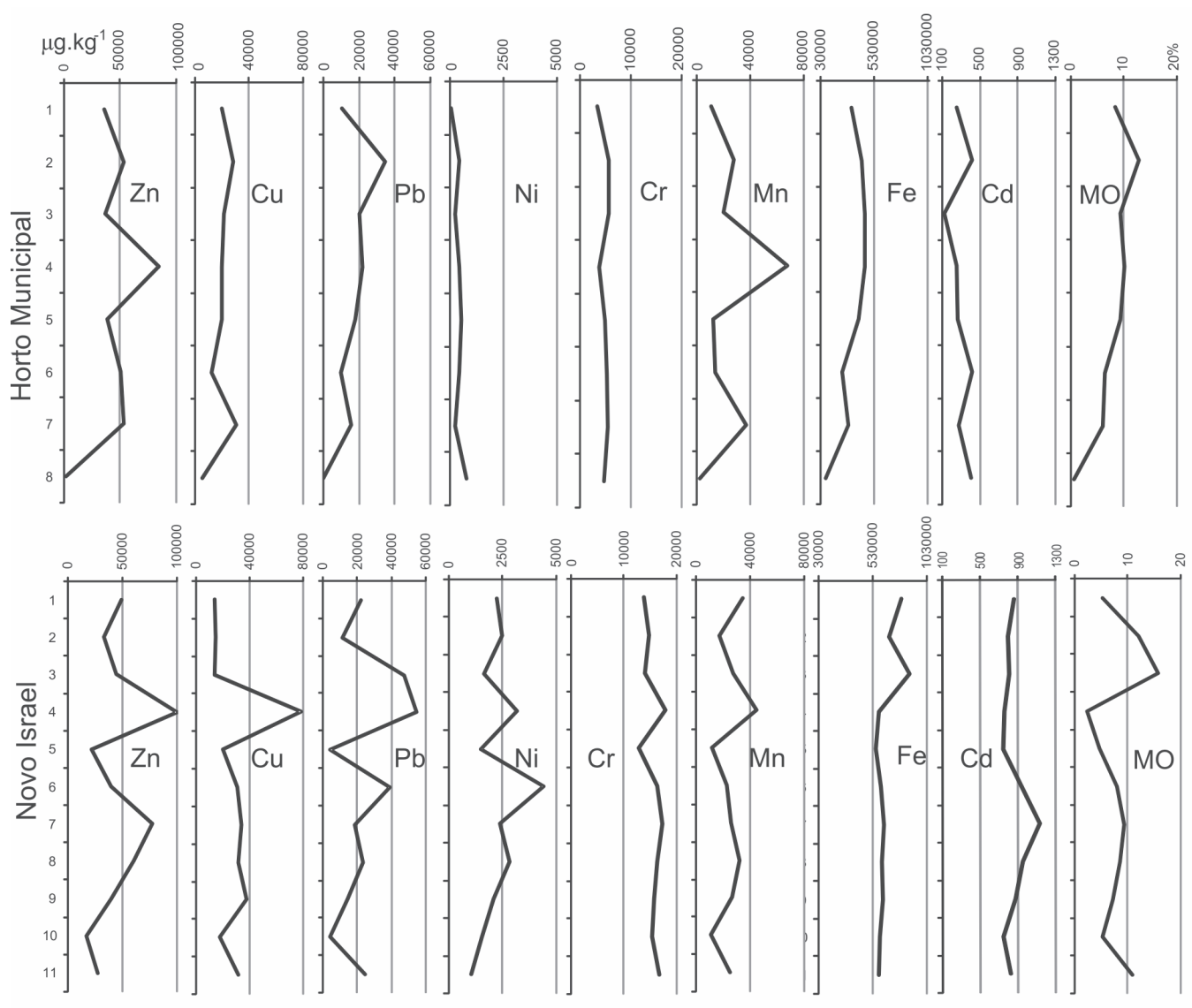

Figura 5 - Distribuição da concentração total dos elementos-traço em $\mu \mathrm{g} \cdot \mathrm{kg}^{-1}$ e da matéria orgânica (M0) em \% nos solos urbanos do Horto Municipal e de Novo Israel.

natural somente o Fe está acima do limite de detecção no topo do perfil (até $32168 \mu \mathrm{g} \cdot \mathrm{kg}^{-1}$ ) e Ni na porção intermediária (59 $\mu \mathrm{g} \cdot \mathrm{kg}^{-1}$ ) (Figura 4).

$\mathrm{Na}$ fração matéria orgânica, o Horto Municipal é marcado por elevadas proporçóes de $\mathrm{Zn}$ (até $32168 \mu \mathrm{g} \cdot \mathrm{kg}^{-1}$ ), Cu (até $8936 \mu \mathrm{g} \cdot \mathrm{kg}^{-1}$ ), Mn (até $33218 \mu \mathrm{g} \cdot \mathrm{kg}^{-1}$ ) e Fe (até $30406 \mu \mathrm{g} \cdot \mathrm{kg}^{-1}$ ), especialmente na porção média superior do solo (Figura 4) e por $\mathrm{Pb}, \mathrm{Ni}, \mathrm{Cr}$ e $\mathrm{Cd}$ abaixo do limite de detecção (Tabela 2). Em Novo Israel $\mathrm{Zn}, \mathrm{Cu}, \mathrm{Mn}$ também estão em média mais elevados especialmente na porção intermediária do solo (Figura 4), enquanto Fe é inferior ao do Horto Municipal e $\mathrm{Pb}$ e Ni estão acima do limite de detecção apenas próximo a base do solo (até $36 \mu \mathrm{g} \cdot \mathrm{kg}^{-1}$ ). No solo natural o conteúdo dos elementos é bem inferior ao dos solos urbanos.

A fração oxi-hidróxidos de Fe tem esse elemento como o de conteúdo mais elevado (Figura 4), pois constitui a hematita e goethita presentes nesta fração. No Horto Municipal o conteúdo de $\mathrm{Zn}$, Cu e Mn é inferior a dos hidróxidos amorfos e Pb e Fe são superiores (Tabela 2). Novo Israel, com os teores mais elevados que no Horto Municipal, se caracteriza pela maior concentração de Ni que alcança $1007 \mu \mathrm{g} \cdot \mathrm{kg}^{-1}$. No solo natural a concentração dos elementos é errática e inferior a dos solos urbanos. Cu e Mn são os únicos que estão levemente mais concentrados nesta fração que na dos amorfos de Fe.

A fração residual concentra os elementos contidos nos minerais que não foram solubilizados nas extraçôes anteriores. É nessa fração que todos os elementos estão mais concentrados, especialmente em Novo Israel (Tabela 2). No solo natural os conteúdos de $\mathrm{Ni}, \mathrm{Cr}, \mathrm{Mn}$, Fe e Cd são inclusive mais elevados que no Horto Municipal (Tabela 2). Nesta fração bem como na amorfa e na dos óxi-hidróxidos, o ferro é o elemento mais abundante em quase todo os perfis (Figura 4).

A somatória dos teores das fraçóes de cada elemento ao longo dos perfis indica variaçôes acentuadas (Figura 5). Contudo, no Horto Municipal há um padrão geral, $\mathrm{Zn}, \mathrm{Cu}$, $\mathrm{Pb}, \mathrm{Mn}$ e Fe tendem a aumentar de teor em direção ao topo e $\mathrm{Ni}$ e Cd diminuem e Cr quase não varia. Todos os elementos tem teores menores na superfície em relação a amostra precedente. Em Novo Israel também há variaçóes de teores ao longo do solo. Eles tendem a serem menores na base e maiores na porção intermediária, a amostra 4 que é a que apresenta as maiores concentraçóes de $\mathrm{Zn}, \mathrm{Cu}, \mathrm{Pb}$ e $\mathrm{Mn}$ e em relação 
a amostra 6 para Ni, amostra 3 para Fe e amostra 7 para Cd. Ao contrário do Horto Municipal os teores aumentam na superfície em relação a amostra precedente exceto para $\mathrm{Cu}, \mathrm{Ni}$ e Cr. Em relação a matéria orgânica somente $\mathrm{Fe} \mathrm{e} \mathrm{Pb}$ mostram o mesmo padráo de distribuição no Horto Municipal, além de também haver acréscimo de teor para o topo do solo, mas decréscimo em superfície (Figura 5). No Novo Israel o padrão da matéria orgânica se assemelha ao do Fe e na base do solo aos do $\mathrm{Zn}, \mathrm{Cu}, \mathrm{Pb}, \mathrm{Mn}$ e $\mathrm{Cd}$.

\section{DISCUSSÃO E CONCLUSÃO}

A quantidade de resíduos depositados nos dois locais estudados é desconhecida, contudo considerando os efeitos de degradação e compactação natural do material, a formação de pelo menos $7 \mathrm{~m}$ de solo no Horto Municipal e de $10 \mathrm{~m} \mathrm{em}$ Novo Israel indica um volume considerável. Apesar disso, e da grande quantidade de matéria orgânica em relação ao solo natural e do componente amorfo identificado, eles refletem a composição mineralógica do solo natural.

Os dois solos estudados estão altamente contaminados em elementos-traços quando comparados com o solo natural, em termos absolutos ambos tem aproximadamente a mesma sequência de concentração dos elementos: no Horto Municipal $\mathrm{Fe}>\mathrm{Zn}>\mathrm{Mn}>\mathrm{Cu}>\mathrm{Pb}>\mathrm{Cr}>\mathrm{Ni}>\mathrm{Cd}$ e em Novo Israel $\mathrm{Fe}>\mathrm{Zn}>\mathrm{Cu}>\mathrm{Mn}>\mathrm{Pb}>\mathrm{Cr}>\mathrm{Ni}>\mathrm{Cd}$ (Tabela 3). As maiores acumulaçóes foram nas fraçóes hidróxido de $\mathrm{Fe}$ amorfo e

Tabela 3 - Ordem decrescente de contribuição dos elementos nas frações analisadas.

\begin{tabular}{|c|c|c|}
\hline Fração & Local & Elementos \\
\hline \multirow{3}{*}{ Solúvel em água } & $\mathrm{NI}$ & $\mathrm{Zn}>\mathrm{Cu}$ \\
\hline & $\mathrm{HM}$ & $\mathrm{Zn}>\mathrm{Mn}>\mathrm{Cu}>\mathrm{Ni}>\mathrm{Pb}$ \\
\hline & $\mathrm{N}$ & $\mathrm{Zn}>\mathrm{Fe}>\mathrm{Mn}$ \\
\hline \multirow{3}{*}{ Trocável e adsorvida } & $\mathrm{NI}$ & $\mathrm{Zn}>\mathrm{Mn}>\mathrm{Cu}>\mathrm{Pb}>\mathrm{Ni}>\mathrm{Cd}$ \\
\hline & HM & $\mathrm{Zn}>\mathrm{Mn}>\mathrm{Cu}>\mathrm{Pb}>\mathrm{Ni}>\mathrm{Fe}$ \\
\hline & $\mathrm{N}$ & $\mathrm{Ni}>\mathrm{Fe}>\mathrm{Zn}>\mathrm{Mn}>\mathrm{Pb}>\mathrm{Cu}>\mathrm{Cd}$ \\
\hline \multirow{3}{*}{$\begin{array}{l}\text { Hidróxidos de Fe } \\
\text { amorfos }\end{array}$} & $\mathrm{NI}$ & $\mathrm{Fe}>\mathrm{Zn}>\mathrm{Mn}>\mathrm{Cu}>\mathrm{Pb}$ \\
\hline & HM & $\mathrm{Fe}>\mathrm{Zn}>\mathrm{Cu}>\mathrm{Mn}>\mathrm{Pb}>\mathrm{Ni}$ \\
\hline & $\mathrm{N}$ & $\mathrm{Fe}>\mathrm{Ni}$ \\
\hline \multirow{3}{*}{ Matéria orgânica } & $\mathrm{NI}$ & $\mathrm{Zn}>\mathrm{Fe}>\mathrm{Mn}>\mathrm{Cu}$ \\
\hline & $\mathrm{HM}$ & $\mathrm{Fe}>\mathrm{Zn}>\mathrm{Mn}>\mathrm{Cu}>\mathrm{Pb}>\mathrm{Ni}$ \\
\hline & $\mathrm{N}$ & $\mathrm{Fe}>\mathrm{Zb}>\mathrm{Ni}>\mathrm{Mn}>\mathrm{Cu}>\mathrm{Pb} \sim \mathrm{Cr} \sim \mathrm{Cd}$ \\
\hline \multirow{3}{*}{ Oxi-hidróxidos de Fe } & $\mathrm{NI}$ & $\mathrm{Fe}>\mathrm{Pb}>\mathrm{Zn}>\mathrm{Mn}>\mathrm{Cu}$ \\
\hline & HM & $\mathrm{Fe}>\mathrm{Zn}>\mathrm{Pb}>\mathrm{Cu}>\mathrm{Mn}>\mathrm{Ni}$ \\
\hline & $\mathrm{N}$ & $\mathrm{Fe}>\mathrm{Cu}>\mathrm{Mn}$ \\
\hline \multirow{3}{*}{ Residual } & $\mathrm{NI}$ & $\mathrm{Fe}>\mathrm{Zn}>\mathrm{Pb}>\mathrm{Cu}>\mathrm{Cr}>\mathrm{Mn}>\mathrm{Ni}>\mathrm{Cd}$ \\
\hline & HM & $\mathrm{Fe}>\mathrm{Zn}>\mathrm{Cu}>\mathrm{Pb}>\mathrm{Cr}>\mathrm{Mn}>\mathrm{Ni}>\mathrm{Cd}$ \\
\hline & $\mathrm{N}$ & $\mathrm{Fe}>\mathrm{Cr}>\mathrm{Mn}>\mathrm{Cu}>\mathrm{Ni}>\mathrm{Cd}>\mathrm{Zn}$ \\
\hline \multirow{3}{*}{ Total } & $\mathrm{HM}$ & $\mathrm{Fe}>\mathrm{Zn}>\mathrm{Mn}>\mathrm{Cu}>\mathrm{Pb}>\mathrm{Cr}>\mathrm{Ni}>\mathrm{Cd}$ \\
\hline & $\mathrm{NI}$ & $\mathrm{Fe}>\mathrm{Zn}>\mathrm{Cu}>\mathrm{Mn}>\mathrm{Pb}>\mathrm{Cr}>\mathrm{Ni}>\mathrm{Cd}$ \\
\hline & $\mathrm{N}$ & $\mathrm{Fe}>\mathrm{Cr}>\mathrm{Mn}>\mathrm{Cu}>\mathrm{Zn}>\mathrm{Ni}>\mathrm{Cd}>\mathrm{Pb}$ \\
\hline
\end{tabular}

óxi-hidróxidos de Fe seguidas da matéria orgânica (Tabela 4) e entre os elementos $\mathrm{Zn}$, Cu e $\mathrm{Mn}$ foram os que mais se acumularam (+ de 1161 vezes) inclusive $\mathrm{Pb}$ na fração residual do Horto Municipal (7405 vezes) e Ni (1697 vezes) em Novo Israel. Comparativamente, essas fraçóes tiveram em geral maior enriquecimento em elementos no Horto Municipal, enquanto as mais biodisponíveis e a residual acumularam-se mais em Novo Israel.

Quando os elementos são sorvidos por interações eletrostáticas ou de van der Walls por complexos com baixa estabilidade (Camargo e Alleoni 2001; Sposito 1989) eles são os realmente biodisponíveis para a água e vegetaçáo. Nesse tipo de ligação os elementos podem ser trocados facilmente por outros (troca iônica) devido à agitaçâo térmica quando há variaçôes no $\mathrm{pH}$ e, portanto são fonte permanente de elementos para as soluçôes (Kabata-Pendias e Pendias 1987) e, conseqüentemente para o meio ambiente. Nos solos urbanos estudados o $\mathrm{Zn}$ com o teor mais elevado exceto em relação ao Fe nas fraçóes óxi-hidróxidos e residual, é o mais reativo e é seguido, principalmente do $\mathrm{Mn}$ e $\mathrm{Cu}$ nas fraçóes mais biodisponíveis e de $\mathrm{Pb}$ e $\mathrm{Cu}$ nas fraçóes óxi-hidróxido (Tabela 4).

Os compostos orgânicos na forma de alcoóis, fenóis ou ácidos carboxílicos, alcenos, quinonas, aminas e compostos alifáticos, identificados nos resíduos estudados, e o pH mais alcalino sugerem que os resíduos já passaram da fase anaeróbica

Tabela 4 - Taxa de acumulação no solo urbano do Horto Municipal e Novo Israel em relação ao solo natural (ND quando os teores foram inferiores a $<0,5 \mu \mathrm{g} \cdot \mathrm{kg}^{-1} 0$ que impediu 0 cálculo).

\begin{tabular}{|c|c|c|c|c|c|c|}
\hline \multirow[b]{2}{*}{ Elemento } & \multicolumn{6}{|c|}{ Frações } \\
\hline & $\begin{array}{l}\text { Solúvel } \\
\text { em água }\end{array}$ & $\begin{array}{l}\text { Trocável e } \\
\text { adsorvida }\end{array}$ & $\begin{array}{c}\text { Óxidos } \\
\text { de Fe } \\
\text { amorfos }\end{array}$ & $\begin{array}{l}\text { Matéria } \\
\text { orgânica }\end{array}$ & $\begin{array}{c}\text { Oxi- } \\
\text { hidróxidos } \\
\text { de Fe }\end{array}$ & Residual \\
\hline \multicolumn{7}{|c|}{ Horto Municipal } \\
\hline $\mathrm{Zn}$ & 0,9 & 157 & 10828 & 80 & 6145 & 49 \\
\hline $\mathrm{Cu}$ & 23 & 19 & 5603 & 2393 & 83 & 2,4 \\
\hline $\mathrm{Pb}$ & ND & 8 & 72 & ND & 8935 & 7405 \\
\hline $\mathrm{Ni}$ & ND & 0,1 & ND & ND & ND & 0,3 \\
\hline $\mathrm{Cr}$ & ND & ND & ND & ND & ND & 0,5 \\
\hline $\mathrm{Mn}$ & ND & 109 & 5838 & 485 & 1990 & 0,4 \\
\hline $\mathrm{Fe}$ & ND & ND & 20 & 1,4 & 30 & 0,2 \\
\hline $\mathrm{Cd}$ & ND & 0,2 & ND & ND & ND & 0,3 \\
\hline \multicolumn{7}{|c|}{ Novo Israel } \\
\hline $\mathrm{Zn}$ & 1 & 115 & 8503 & 33 & 8955 & 88 \\
\hline $\mathrm{Cu}$ & 32 & 42 & 5347 & 2621 & 130 & 6 \\
\hline $\mathrm{Pb}$ & 5 & 29 & 3420 & 4 & 3597 & 16419 \\
\hline $\mathrm{Ni}$ & 16 & 1,6 & 26 & 0,1 & 236 & 1697 \\
\hline $\mathrm{Cr}$ & ND & ND & ND & ND & ND & 1,5 \\
\hline $\mathrm{Mn}$ & 2 & 139 & 3584 & 2,3 & 1161 & 1,4 \\
\hline $\mathrm{Fe}$ & ND & 2,8 & 20,5 & 2,8 & 27,6 & 1,1 \\
\hline $\mathrm{Cd}$ & ND & ND & ND & ND & ND & 0,9 \\
\hline
\end{tabular}


ácida e estão na fase de geração de metano e humificação. Nessa condiçâo a mobilidade dos elementos é baixa, pois além dos grupos funcionais da matéria orgânica, que formam ligaçôes fracas de troca iônica em condiçôes de $\mathrm{pH}$ mais ácido e covalentes em pH mais alcalino (Stevenson 1994; Lu et al. 2003), formam-se os amorfos de Fe, sulfetos e carbonatos que tem alta capacidade de imobilizar metais (Bozkurt et al. 2000). Além disso, o ambiente tropical chuvoso ao qual estáo submetidos os solos estudados intensifica o desenvolvimento de óxi-hidróxidos de Fe que chegam a formar crostas com até $2 \mathrm{~m}$ de espessura (Peixoto e Horbe 2008).

A retenção mais elevada no Horto Municipal deve estar relacionada ao maior tempo de interação dos constituintes mais estáveis do resíduo e a maior degradação e humificação da matéria orgânica como indica a correlação entre $\mathrm{Zn}, \mathrm{Cu}, \mathrm{Pb}$, $\mathrm{Mn}$, Fe e matéria orgânica(r $>0,67)$, enquanto em Novo Israel os elementos se correlacionam entre si $(r>0,65)$, mas não com o Fe e a matéria orgânica $(r<0,40)$. No solo natural somente $F e$, $\mathrm{Zn}, \mathrm{Cr}$ e matéria orgânica mantêm correlaçôes significativas $(r<0,52)$. A maior retençáo no Horto Municipal deve estar também relacionada ao caráter eletroquímico tanto positivo quanto negativo como indicado pelo $\Delta \mathrm{pH}$, enquanto em Novo Israel, que é mais jovem, é predominantemente positivo sugere menor capacidade de sorver metais e menor humificação. Contudo, modificaçôes na estabilidade da matéria orgânica associada a sua oxigenação e conseqüente acidificação, podem facilmente liberar os elementos sorvidos para as soluçôes. Esse fato está ocorrendo no Horto Municipal, onde há decréscimo de todos os elementos na superfície, enquanto em Novo Israel o aumento de $\mathrm{Zn}, \mathrm{Pb}, \mathrm{Mn}$, Fe e Cd (Figura 5) indica maior estabilidade.

Apesar da abundância de matéria orgânica nos solo (até $15,8 \%$ ) as frações dos óxidos amorfos e óxi-hidróxidos de Fe têm maior capacidade de acumulação (Tabela 4). Restos metálicos, chapas, fios e pregos encontrados especialmente em Novo Israel, são os responsáveis pelos conteúdos mais elevados em Fe e da maioria dos demais elementos na fração dos hidróxidos amorfos. Os constituintes amorfos, bem como o baixo grau de ordenamento da caulinita encontrada nos resíduos, facilitam e elevam a capacidade de troca catiônica (Melo et al. 2001) e contribuem para o acúmulo de $\mathrm{Zn}, \mathrm{Cu}$, $\mathrm{Pb}$ e $\mathrm{Mn}$ nessa fração e na trocável. Por outro lado, o tempo também é um aliado na fixaçáo dos elementos, pois à medida que os materiais amorfos envelhecem eles tendem a estruturas mais organizadas (Shuman 1975), isto permitiria a acumulação um pouco mais acentuada de $\mathrm{Zn}$ e Cu nessa fraçấo no Horto Municipal. Além disso, a maturaçáo dos resíduos torna o pH menos ácido e facilita a estabilização dos óxi-hidróxidos e a consequentemente fixação dos elementos (Andreottola e Cannas 1997; Bozkurt et al. 2000; Zapusek e Lestan 2009). A maior capacidade de retençáo dos materiais amorfos, também observada em ambientes similares (Flyhammat et al. 1997), pode estar relacionada à matéria orgânica. Esta desestabiliza os minerais herdados do solo, como constatado pelo desordenamento crescente da estrutura da caulinita, e é um dos principais agentes inibidores no processo de formação dos óxi-hidróxidos de Fe (Sposito 1989; Schwertmann e Cornell 1991), mas estabiliza os amorfos e, consequentemente a capacidade de adsorçáa de elementos.

É interessante o grande acúmulo de $\mathrm{Pb}$ na fraçáo residual e óxi-hidróxido de Fe. A não ser que esse elemento tenha sido adicionado em uma forma cristalina estável, tanto no Horto Municipal como em Novo Israel, há forte indício de rápido processo de estabilização desse elemento, especialmente quando se considera o seu menor acúmulo na fração amorfa. Essa estabilização, que deve ocorrer também com os demais elementos, mas em uma taxa mais lenta, deve estar associada à baixa mobilidade desse elemento no ambiente superficial que pode precipitar como carbonato em $\mathrm{pH}>5.5$ (Drever 1997) e ao efeito de envelhecimento e desidratação dos amorfos de Fe (Zapusek e Lestan 2009). Nesse processo eles tendem para fases mais cristalinas e residuais e, portanto com maior predominância de ligaçôes covalentes com capacidade de difundir os elementos sorvidos para o interior da estrutura (Barrow 1979).

Este estudo mostra que parte dos elementos químicos está retida no solo o que minimiza o potencial atual de impacto ambiental. Contudo, a associação com as fases mais móveis e a expansão da pluma de contaminação no período chuvoso constatada por Rocha e Horbe (2006), indicam que o pH ácido da água da chuva em Manaus $(\mathrm{pH}=4,1$ - Honório et al. 2010) tem capacidade de mobilizar os elementos retidos no solo exatamente por estarem mais associados às fases mais biodisponíveis (fraçôes solúvel, trocável/adsorvida, amorfa e matéria orgânica) e contaminar a água subterrânea. Prevê-se contaminação semelhante no entorno do Horto Municipal, mas em menor escala já que o conteúdo dos elementos é menor e há maior estabilidade dos solos, apesar dos indícios de remobilização serem evidentes no topo. A possibilidade que esses solos sejam revolvidos no futuro pode potencializar a liberação de elementos para o meio ambiente e agravar a contaminação da água subterrânea.

\section{AGRADECIMENTOS}

Ao curso de pós-graduação em Geociências da UFAM pelo apoio logístico, a CAPES pela bolsa ao primeiro autor e ao CNPq pela bolsa de produtividade ao segundo autor. Aos revisores pelas suas correçôes e sugestóes.

\section{BIBLIOGRAFIA CITADA}

Alcântara, M.A.K.; Camargo, O.A. 2001. Retarding factor and dispersion-diffusion coefficient fot chromium (III) in hard weathering soil influenced by $\mathrm{pH}$, texture and organic matter. 
Revista Brasileira de Ciência do Solo, 25: 209-216. (in Portuguese, with abstract in English).

Banat, K.M.; Howari, F.M.; Al-Hamad, A.A. 2005. Heavy metals in urban soils of central Jordan: Should we worry about their environmental risk? Environmental Research, 97: 258-273.

Barbosa, R.M.; Otero, O.M.F. 1999. Characterization of polution plume originated by a landfill. Geochimica Brasiliensis, 13: 51-65. (in Portuguese, with abstract in English).

Barrow, N.J. 1989. The reaction of plant nutrients and pollutants with soil. Australian Journal of Soil Research, 27: 475-492.

Bozkut, S.; Moreno, L.; Neretnieks, I. 1999. Long-term fate of organics in waste deposits and its effect on metal release. The Science of the Total Environment 228: 135-152.

Bozkurt, S.; Moreno, L.; Neretnieks, I. 2000. Long-term processes in waste deposits. The Science of the Total Environment 250: 101-121.

Camargo, O.A.; Alleoni, L.R.F. 2001. Micronutient and toxic elements in soil. In: Ferreira, M.E.; Cruz, M.C.P.; Raij, B. V; Abreu, C.A. (Org.). Micronutrientes e elementos tóxicos na agricultura. Jaboticabal: CNPq, FAPESP/ POTAFOS, 35-48. (in Portuguese, with abstract in English).

Covelo, E.F.; Vega, F.; Andrade, M.L. 2007. Heavy metal sorption and desorption capacity of soils containing endogenous contaminants. Journal of Hazardous Material, 143, 419-430.

Drever, J.I. 1997. The geochemistry of natural waters - surface and groundwater environments. Prentice Hall, NY, USA. 237pp.

EMBRAPA - Empresa Brasileira de Pesquisa Agropecuária 1997. Handbook of methods in soil analysis. 2 ed. Ministério da Agricultura e do Abastecimento, Rio de Janeiro, Brasil. 370 pp. (in Portuguese).

Ensinas, A.V. 2003. Studied of biogás generation in Delta landfill in Campinas - SP. Master Dissertation, Faculdade de Engenharia Mecânica, Universidade Estadual de Campinas, Campinas, São Paulo. 125pp. (in Portuguese with abstract in English).

Flyhammar, P. 1997. Estimation of heavy metal transformation in municipal solid waste. The Science of the Total Environment 198: 123-133.

Fontes, M.P.F.; Camargo, O.A; Sposito, G. 2001. Eletrochemistry of colloidal particulates and its relationship with mineralogy of hard weathering soils Scientia Agricola, 56: 627-646. (in Portuguese, with abstract in English).

Fontes, M.P.F.; Gomes, P.C. 2003. Simultaneous competitive adsorption of heavy metals by the minerals matrix of tropical soils. Applied Geochemistry 18, 795-804.

Hinckley, D.N. 1963.Variability in "crystallinity" values among the kaolin deposits of the coastal plain of Georgia and South Carolina, p. 23-28. In: Swineford, A., (Ed.) Clay and clay minerals national conference, vol. 11, Ottawa, Proceedings. New York.

Horbe, A.M.C.; Horbe, M.A.; Suguio, K. 2004. Tropical Spodosols in northeastern Amazonas State, Brazil. Geoderma, 119: 55-68.

Honório, B.A.D.; Horbe, A.M.C.; Seyler, P.T. 2010. Chemical composition of rainwater in western Amazonia - Brazil. Atmospheric Research, 98: 416-425.
Kabata-Pendias, A.; Pendias, H. 1987. Trace elements in soils and plants, CRC Press. Boca Raton, USA. 238 pp.

Keller, C.and Vedy, J.C. 1994. Distribution of copper and cadmium fractions in two forest soils. Journal of Environmental Quality, 23: 987-999

Lã, O.R.; Barra, C.M.; Sobrinho, N.M.B. do A.; Mazur, N.; Velloso, A.C. X. 2003. Evaluation of sequential extraction methods of Tessier, Keller and Miller in native iron determination in three soil types: Organic, Brunizen e Latosol. Quimica Nova, 26: 323330. (in Portuguese, with abstract in English).

Lima, L.M.Q. 1991. Garbage: treatment and bioremediation. Hemus Editora Ltda, São Paulo, Brasil. 125 pp. (in Portuguese).

Lu, Y.; Gong, Z.; Zhang, G.; Burghardt, W. 2003. Concentration and chemical speciation of $\mathrm{Cu}, \mathrm{Zn}, \mathrm{Pb}$ and $\mathrm{Cr}$ of urban soils in Nanjing, China Geoderma, 115: 101-111.

Mantei, E.J.; Sappington, E.J. 1994. Heavy metal concentration in sediments of stream affected by sanitary landfill: A comparison of metal enrichment in two size sediment fractions. Environmental Geology, 24: 287-292

McBride, M.; Sauvé, S.; Hendershot, W. 1997. Solubility control of $\mathrm{Cu}, \mathrm{Zn}, \mathrm{Cd}$ and $\mathrm{Pb}$ in contaminated soils. European Journal of Soil Science, 48: 337-346.

Melo, V.F.; Singh, B.; Schaefer, C.E.G.R.; Novais, R.F. Fontes, M.P.F. 2001. Chemical and mineralogical properties of kaolinite - Rich Brazilian soils. Journal of the Soil Science Society of America, 65: 1324-1333.

Miller, W.P.; Martens, D.C.; Zelazny, L.W. 1986. Effect of sequence in extraction of trace metals from soils. Soil Science, 50: 598-601.

Peixoto, S.F.; Horbe, A.M.C. 2008. Bauxite in the northern of Amazonas. Revista Brasileira de Geociências, 38: 406-422. (in Portuguese, with abstract in English).

Rocha, L.C.R.; Horbe, A.M.C. 2006. Contamination provoked by a garbage dump in the Alter do Chão aquifer in Manaus-AM. Acta Amazônica, 36: 307-312. (in Portuguese, with abstract in English).

Schwertmann, U.; Cornell, R.M. 1991. Iron Oxides in the Laboratory - Preparation and Characterization. VCH Publishers, New York. 570 pp.

Shuman, L.M. 1975. The effect of soil properties on zinc adsorption by soils. Soil Science Society of America Journal 39: 454-458.

Sisinno, C.L.S.; Moreira, J.C. 1996. Evaluation of environmental contamination and pollution in a área influenced by a landfill at Morro do Céu, Niterói, Brasil. Cadernos de Saúde Pública, 12: 515-523. (in Portuguese, with abstract in English).

Sodré, F.F.; Lenzi, E.; Costa, A.C.S. da. 2001. Physical-chemical models of adsortion in the study of copper behavior in clayey soils. Quimica Nova, 24: 324-330 (in Portuguese, with abstract in English).

Sposito, G. 1989. The Chemistry of Soils. Oxford University Press, USA. 345 pp.

Stevenson, F.J. 1994. Humus Chemistry: genesis, composition, reactions. Wiley, New York, USA. 268 pp. 
Tessier, A.; Campbell, P.G.C.; Bisson, M. 1979. Sequential Extraction Procedure for the Speciation of Particulate Trace Metal. Analytical Chemistry, 51: 844-851.

Wilcke, W.; Müller, S; Kanchanakool, N.; Zech, W. 1998. Urban soil contamination in Bangkok: Heavy metal and aluminium partition in topsoils. Geoderma, 86: 211-228.
Zapusek, U.; Lestan, D. 2009. Fractionation, mobility and bioaccessibility of $\mathrm{Cu}, \mathrm{Zn}, \mathrm{Cd}, \mathrm{Pb}$ and $\mathrm{Ni}$ in aged artificial soil mistures. Geoderma, 154: 164-169.

Zhang, C.; Tang, Y.; Luo, L.; Xu, W. 2009. Outlier identification and visualization for $\mathrm{Pb}$ concentrations in urban soils and its implications for identification of potential contaminated land. Environmental Pollution, 137: 3083-3090.

Recebido em 30/10/2010

Aceito em 12/12/2010 
